\title{
Theory, Practice and Innovation-The Exploration of High School Physical Education Program Reform and the Club Teaching Mode
}

\author{
Qing Ma
}

\section{Xi'an FanYi University, Xi'an, Shanxi 710105}

\begin{abstract}
The implementation of sports club teaching in colleges and universities not only enriches the college's physical education teaching activities, but also provides a show stage for students' sports hobbies and expertise and exercise the organization and management of students. However, with the development of many college sports clubs, some shortcomings and problems gradually exposes. This article firstly starts from the theoretical aspects of physical education reform to discuss the teaching mode of the club, and propose the implementation of the program and create a path in an innovative way. Hope to offer a new mode for college PE curriculum reform and club teaching.
\end{abstract}

Keyword: Theory, Practice and Innovation; Curriculum Reform; Club Teaching Mode

\section{理论、实践与创新}

\section{-高校体育课程改革与俱乐部教学模式探索}

\author{
马庆 \\ （西安翻译学院, 陕西 西安 710105 )
}

摘要: 在高校中实施体育俱乐部教学, 不但使高校的体育教学活动更加丰富, 同时也为学生的体育爱好和特长提供了展示 的舞台, 锻炼了学生的组织与管理能力。然而随着许多高校体育俱乐部的发展, 一些不足和问题逐渐暴露出来。本文首先从 理论方面入手探讨体育教学改革和俱乐部教学模式的动因, 又创新性的提出实施方案和创建路径, 希望能够为高校体育课程 改革与俱乐部教学提供可借鉴的一种新型模式。

关键词:理论、实践与创新; 课程改革; 俱乐部教学模式

引言 :

改革开放 30 多年来, 我国学校体育教学工作取得了显著的成绩。但是随着教育教学形式的不断向前发 展, 现有的教学指导思想、教学方法、教材内容等方面存在偏差或落后于现实, 许多现象和问题使人们感 到困惑。例如: 我国大学生身体素质逐年下降; 青少年心理脆弱, 体育锻炼意识不强; 近年来大学生跑步 “心脏粹死” 频发等现象已引起社会广泛关注。

解决体育教学现有的问题, 必须改变以教师为主导传授动作、技术为中心的传统型教育模式, 向着增 强学生体质, 培养终生体育爱好为目的的教育模式转变, 深化教学改革, 摆脱传统的体育教学思想和体育 教学模式, 建立一个新的课程体系, 即俱乐部制, 实施俱乐部型体育教学模式有利于增强大学生的体育意 识、兴趣与爱好; 有利于保持体育教学和课外锻炼的连续性; 有利于把大学生的体育教育过程延伸到高等 教育的全过程; 为终身体育奠定基础。

\section{1 研究对象}

西安翻译学院体育课程教学

\section{2. 研究方法}




\section{1 文献资料法}

利用知网、图书馆期刊查阅了国内关于普通高校体育教学改革及俱乐部教学改革的有关文献资料和相 关的体育理论等方面的书籍, 对以上所查阅的资料文献进行了总结归纳。

\section{2 访谈法}

通过现场和电话方式对 2 所公办高校和 6 所民办高校的体育部长、体育专业教授进行访谈，主要内容 为, 普通高校体育课教学俱乐部模式以及俱乐部模式教学在实施过程中存在的困难和急需解决的问题、学 生锻炼的形式及场地保障等内容。

\section{3 实践法}

制定了西安翻译学院体育课程改革与俱乐部教学实施方案, 在两学期体育教学中按照方案进行教学活 动。

\section{3. 研究背景}

依据中共中央国务院关于深化教育改革全面推进素质教育的决定和全国普通高等学校体育课程教学 指导纲要的精神, 新的纲要指出: 根据学校教育的总体要求和体育课程的自身规律, 应面向全体学生开设 多种类型的体育课程，可以打破原有的系别，班级制，重新组合上课，以满足不同层次，不同水平，不同 兴趣的学生的需要, 在教师的指导下, 学生应具有自主选择课程内容, 自主选择任课老师, 自主选择上课 时间的自由度，新指导纲要为高校体育俱乐部的发展提供了强有力的理论依据与政策支持

\section{4. 课程建设}

\section{1 课程改革政策依据与指导思想}

为进一步贯彻、落实《全国普通高等学校教育课程教学指导纲要》和《教育部关于印发〈高等学校体 育工作基本标准>的通知》的文件精神, 深化体育教学改革, 提高教学质量, 促进学生身心健康发展, 以 实现运动参与、运动技能、身体健康、心理健康及社会适应五个领域的基本目标和发展目标，体现 “学生 为本，健康第一”的指导思想。

\section{2 学校重视}

学校领导历来重视学校体育工作的发展和学生身体素质的提高, 要求体育教学必须改变以往的教学模 式以适应学院转型发展的需要, 适应新的人才培养方案的实施, 学校提出了体育教学以体育俱乐部的形式 进行改革的目标, 针对学生不同的运动基础与对体育项目兴趣爱好, 采用更加灵活的教学模式, 积极推动 学校体育教学、训练、竞赛、课余体育锻炼等活动，营造健康向上的校园体育文化氛围。

\section{3 体育俱乐部改革的实施}

\section{3.1 大一年级 “健康体适能” 课程教学内容改革效果明显}

为提高大一学生的身体素质与体质健康测试达标率，体育部调整了大一年级的体育课程内容，及以评 价学生 “健康体适能” 的两项指标—— “心肺耐力” 与 “身体柔韧素质” 作为主要教学内容, 改变了以往 直接让大一新生进行体育选项教学的做法; 并提出了 “堂堂三千米” 的教学内容要求。新的课程设置, 注 重加强学生身体素质, 尤其是增强了大一学生的耐力跑能力和肺活量水平。运动体适能实施以来效果显 著, 具体体现在学生体质测试各项成绩与往年相比有明显的提高, 800 米 (女生)、1000 米（男生）的成 绩及格率达大幅提高，在测试过程中学生状态良好，没有出现晕倒或不能完成测试的现象，测试后身体状 
况反映较好, 肺活量测试成绩在现有标准下都有不同程度的提升; 由于加强身体柔韧性练习, 在坐位体前 屈、立定跳远等项目上大一学生也表现出色, 与本次测试的其他年级对比优势明显。

\section{3.2 体育俱乐部教学模式探索初见成效}

俱乐部体育教学模式改革是本学期学校提出的重点教改项目。体育部积极落实体育俱乐部实施方案, 在学习借鉴国内与省内同类兄弟院校经验和认真研究体育教学俱乐部模式运行特点、规律的基础上，结合 我校实际情况制定了 “一课一活动” 的实施方案; 以运动代表队、学生体育社团、上课学生为主体共建立 篮球、足球、排球、羽毛球、乒乓球、网球、健美操、形体与瑜伽、体育舞蹈、定向越野、健身健美、武 术养生、散打、轮滑等 14 个体育俱乐部, 各俱乐部完善组织结构, 制定活动方案, 以课后活动、训练、 校内竞赛为组织形式开展俱乐部活动, 坚持一课一活动的原则。由于各项目的特点不同, 每个俱乐部制定 了不同的活动方式。

体育俱乐部开设情况一览表

\begin{tabular}{|c|c|c|c|c|}
\hline 俱乐部类型 & 指导类型 & 人 数 & 活动时间 & 活动类型 \\
\hline 羽毛球俱乐部 & 教师、院队队员 & 250 人 & 9、10 节 & 活动、竞赛 \\
\hline 散打俱乐部 & 教师、武术协会 & 75 人 & 9、10 节 & 活动、竞赛 \\
\hline 定向越野俱乐部 & 教师、院队队员 & 100 人 & 9、10 节 & 活动、竞赛 \\
\hline 篮球俱乐部 & 教 师 & 100 人 & 9、10 节 & 活动、竞赛 \\
\hline 排球俱乐部 & 教 师 & 50 人 & 9、10 节 & 活动、竞赛 \\
\hline 足球俱乐部 & 教 师 & 70 人 & 9、10 节 & 活动、竞赛 \\
\hline 健美操俱乐部 & 教 师 & 100 人 & 9、10 节 & 活动、竞赛 \\
\hline 网球俱乐部 & 教 师 & 50 人 & 9、10 节 & 活动、竞赛 \\
\hline 武术俱乐部 & 教 师 & 50 人 & 9、10 节 & 活动、竞赛 \\
\hline 健身健美俱乐部 & 教 师 & 30 人 & 9、10 节 & 活动、竞赛 \\
\hline 轮滑俱乐部 & 教师、轮滑协会 & 50 人 & 9、10 节 & 活动、竞赛 \\
\hline
\end{tabular}

\section{3.3 积极体育俱乐部项目类型}

体育部在现有体育俱乐部的基础上, 根据学生需求和喜好, 结合学院场地、器材、师资等条件对各俱 乐部进行完善和建设, 例如学生喜欢的羽毛球、乒乓球、健美操、网球、轮滑等俱乐部在条件允许的情况 下多开班级、多吸收会员。为保证学生体育方面的兴趣和爱好得以实现, 体育部加大对教师的培训和外出 
学习, 丰富教师的专业技能和体育理论水平, 对于学生喜爱的项目多开多设, 本学期经体育部申请学院同 意在西区新建了 4 个地掷球场地, 教师经过培训后下学期开设这一广受欢迎的新兴项目, 根据场地、器材、 授课教师现有的配备的情况，已确定开设两节地掷球课程。

\section{5. 体育课程改革的特色}

\section{1. 课程改革的核心理念 “活动、参与、发展”}

活动是核心: 2011 年版《体育与健康课程标准》指出体育课程是以身体练习为主要手段, 以学习体育 与健康知识、技能和方法为主要内容。体育课程的目标是学校教育阶段学生通过体育教育过程 (体育课堂 教学、课余锻炼、运动训练等) 达到预期的目的。身体活动是体育最本质的特征, 学校体育也只能通过体 育教学与运动竞赛活动, 达到增强学生的体质、提高健康水平的目的。

参与是关键: 学业负担加重、对网络和手机的依赖性、体育锻炼的兴趣较低是阻碍大学生参与体育锻 炼的主要因素, 如何使学生主动的参与体育锻炼, 形成自觉锻炼的习惯与意识是问题的关键 。因此, 如 何通过改革体育课程的教学内容、教学手段, 如何通过体育俱乐部教学模式的打造, 形成 “课内外一体化” 的大学体育课程体系, 提高学生的兴趣与参与水平, 是培养学生主动参与体育锻炼意识的关键。

发展是目标：体育活动过程存在相互竞争、交往与合作的社会特性。学生在体育活动过程中形成的竞 争、交往、和合作意识及行为规范, 将会迁移到日常的生活、学习和工作中去。在体育活动增强学生的社 会交往能力, 有利于发展学生的组织能力、协调沟通能力和团队合作精神, 在大学阶段促进学生各方面成 长。

\section{2 体育俱乐部活动}

体育俱乐部是校园体育活动的重要参与者和组织者。体育课程改革后体育俱乐部按照体育部制定的校 内竞赛计划, 举办校园定向越野比赛、校园足球比赛、校园羽毛球赛团体赛、元旦越野赛, 本次赛事的参 赛队伍、参赛人数是历年来最多的一次, 各院系均派代表队参与竞赛活动。各单项体育俱乐部精心组织、 各系踊跃参加, 全体选手奋力拼搏, 保证了赛事的顺利进行。新成立的体育俱乐部作为本次系类赛的承办 单位, 表现出较强的组织能力、协调能力以及敬业精神，也展现出体育俱乐部改革的成果。

\section{3 体育俱乐部评价体系}

体育课程学习评价应以人为本, 注重学生的全面发展, 淡化竞技色彩, 培养学生的自觉锻炼的习惯, 以 此为前提构建我校体育俱乐部教学模式的评价体系, 使学生客观地了解和评价自己。评价体系主要包括过 程性评价和终结性评价两个方面。过程性评价包括: 出勤率、课堂表现、运动技能、身体素质的进步程度、 平时学生体育锻炼习惯养成的情况; 终结性评价包括技能、身体素质达标考核。新的评价机制以提高学生 的积极性、主动性为目标。

\section{4 体育俱乐部会员资格认定}

初级会员认定: 完成第二学期运动体适能课程, 并通过考试的大一学生即被认定为俱乐部初级会员。 中级会员认定: 大二凡参加体育俱乐部课程教学与活动的学生, 及学期末项目考试达标者, 即被认定 为俱乐部中级会员。

高级会员认定：凡参加院运动代表队训练的学生（体育部选拔认定）、以及参加体育社团活动（学工 部出具证明) 的学生均可被认定为体育俱乐部高级会员, 并可免修体育课 (训练与活动时间由学生自行安 
排，指导教师主要负责训练与活动计划的制定)。

\section{7. 问题与建议}

\section{1 体育部教师 “一专多能” 方面的教学能力有待加强}

由于大学体育课属于公共基础课, 为满足学生选项需求通常要多开设项目, 因此需要教师具有多个体 育项目的教学能力, 体育部多数教师专项运动能力较强, 对于自己所从事的专项技术水平和理论水平都很 高, 其他项目相对较弱, 在转换项目授课时, 能力略显不足。

建议: 加强教师的外出培训力度, 以体育专项培训为主, 从培训项目的深度和广度入手, 在提升教师 专项技术能力的同时多参加其他受学生喜爱的体育项目培训; 教师加强自我学习和提高, 体育部多举办教 研活动、教学交流、公开观摩课、教案评比等活动, 为教师创造相互交流、相互学习的机会, 通过这种方 式提高业务能力, 补齐短板。

\section{2 学校运动场地制约了体育俱乐部活动的开展}

随着体育俱乐部活动全面开展, 学校的体育场地、设施、器材与体育俱乐部的发展出现了矛盾, 体育 场地、设施既要进行体育教学与训练又要满足俱乐部活动的开展, 出现了场地使用冲突的现象, 同时一些 场地规划不合理、使用率低使得较少的活动区域更显紧张。

建议: 合理规划, 在校区原有场地的基础上, 把使用率较低的场地进行改造, 以学生喜闻乐见的项目 为主, 如网球场、轮滑场地、室内活动室 (开展羽毛球、乒乓球、健美操等项目) 进行改建和新建, 满足 学生上课、体育锻炼以及体育俱乐部活动的需求。

\section{3 体育俱乐部课程教学与课余活动时间安排有待整合}

由于体育部担负着体育课程教学与组织俱乐部课外活动双重工作任务; 我们将体育俱乐部课程教学与 活动时间安排在下午 $7 、 8$ 节课同一时间段, 由于各院系课程难以统筹安排在同时段, 体育部任课教师授 课时间-空间受到一定限制, 因此无法在这一时段兼顾俱乐部的教学与课外活动的组织; 目前体育俱乐部 的活动未纳入课程化管理体系，其活动的组织仍 “无政府” 状态。

建议：为保证各俱乐部活动开展效果，建议教务处在课表安排时，尽量将“大二”同一院（系)、同 一班级的体育课程与俱乐部活动安排在两个不同的 7、8 节课次时间段, 并将每周一次的校代表队训练与 每周一次的俱乐部活动时间整合为两个教学课次纳入正式课程体系, 以保证俱乐部课外活动和体育代表队 训练工作的统一组织与 “一体化” 管理。

\section{8. 结论}

我校通过近一年的体育教学改革探索和实践,体育俱乐部教学模式的优势已初步显现, 体育俱乐部教 学模式逐步形成, 体育俱乐部教学模式探索和建立科学的、合理的、可操作的体育俱乐部教学模式, 有利 于促进和深化高校的体育教学改革。体育部将继续深化体育教学改革, 大力实施和完善体育俱乐部教学模 式。

\section{参考文献:}

[1]国家教育部. 全国普通高校体育俱乐部教学指导纲要 [M]. 北京: 人民体育出版社, 2002.

[2]季测, 胡增荦. 体育教育展望 $[\mathrm{M}]$. 上海:华东师范大学出版社 社, 2001.

[3]刘志敏. 对我国普通高校体育俱乐部的比较研究 [U]. 北京体育大学学报, 2001 (1). 
[4]邹师, 冯火红. 我国普通高校体育俱乐部的类型与特色研究 [U]. 北京体育大学学报, 2003(1).

[5]谢庆伟, 秦华奇运用150构建高校体育俱乐部教学质量管理体系的研究田沈阳体育学院学报, 2012, 01:99一102

[6]周威, 周爱光, 李敏卿. 对高校公共体育课实施体育俱乐部教学的研究 [J]. 广州体育学院学报, 2003, 23(2) :81-84.

[7]欧阳萍.我国高校体育俱乐部教学模式分析与发展对策 $[J]$.江西师范大学学报, 2008, (3) : 376-378.

[8] 冯寿海. 试析高校体育俱乐部的运作方式与管理 [J]. 吉林体育学院学报, 2003, (3) :53.

[9]兰健. 普通高校群众活动暨单项体育俱乐部创建的构想与设计 $[J]$. 山东体育学院学报, 2001, (3) :41-42.

[10] 白志红. 对发展我国青少年体育俱乐部的若干思考 [J]. 体育成人教育学刊，2003，（1）：61-62.

\section{Reference:}

[1] Ministry of Education. Teaching Outline of Sports Club Teaching in Colleges and Universities in China. [M]. Beijing: People's Sports Publishing House, 2002.

[2] Ji Liu Hu Zenghun. Prospect of Physical Education. [M]. Shanghai: East China Normal University Press, 2001.

[3] Liu Zhimin. A Comparative Study of Sports Clubs in Chinese Universities[U] Journal of Beijing Sport University, 2001 (1).

[4] Zou Shi, Fen Huohong. Research on the Types and Characteristics of Sports Clubs in Ordinary Colleges and Universities in China[U] Journal of Beijing Sport University, 2003 (1).

[5] Xie Qingwei, Qin Huaqi Research on Constructing Teaching Quality Management System of College Sports Club by Using 150, ,2012,01:99-102

[6] Zhou Wei, Zhou Aiguang, Li Minqin. Research on the Implementation of Sports Club Teaching in Public Physical Education in Colleges and Universities [ J]. Journal of Guangzhou Physical Education Institute, 2003,23 (2): 81-84.

[7] Ouyang Ping. Analysis on the Teaching Mode of Sports Club in Colleges and Universities, and Its Development Countermeasures. [J]. Journal of Jiangxi Normal University, 2008, (3): 376-378.

[8] Ma Shouhai The Operation Mode and Management of University Sports Clubs[J]. Journal of Jilin Institute of Physical Education, 2003, (3): 53.

[9] Lan Jian. The Conception and Design of the Mass Activities, and the Establishment of Individual Sports Club in Colleges and Universities J]. Journal of Shandong Institute of Physical Education, 2001, (3): 41-42.

[10] Bai Zhihong Several Thoughts on the Development of Juvenile Sports Clubs in China[J]. Journal of Sports Adult Education, 2003, (1): 61-62. 